\title{
Priming effects of an olfactory food cue on subsequent food-related behaviour
}

\author{
M. Gaillet ${ }^{1,2,3}$, C. Sulmont-Rossé ${ }^{1,2,3}$, S. Issanchou ${ }^{1,2,3}$, C. Chabanet ${ }^{1,2,3}$, S. Chambaron ${ }^{1,2,3}$ \\ ${ }^{1}$ CNRS, UMR6265 Centre des Sciences du Goût et de l'Alimentation, F-21000 Dijon, France. \\ ${ }^{2}$ INRA, UMR1324 Centre des Sciences du Goût et de l'Alimentation, F-21000 Dijon, France. \\ ${ }^{3}$ Université de Bourgogne, UMR Centre des Sciences du Goût et de l'Alimentation, F-21000 \\ Dijon, France.
}

\begin{abstract}
Studies in cognitive psychology have highlighted a link between perception and action, by revealing the non-conscious influence that a cue can have on thinking and doing. The present study aimed at exploring whether an olfactory food cue could have an impact on food choices. We chose fruity odours as olfactory food cues, in order to examine if this kind of olfactory cue could lead individuals to choose fruit and vegetables. In the first experiment, 58 participants were assigned randomly to either a control or a melon-scent condition. In the melon-scent condition, they were unobtrusively exposed to a melon odorant in a waiting room, while in the control condition the room was non-odorized. Then, they all performed a lexical decision task and a task involving choice from a menu. The results showed that participants in the melon-scent condition answered faster only for the word 'melon' in comparison with other tested words. Moreover, participants in the melon-scent condition were more likely than control participants to choose starters with vegetables, but not main courses or desserts with fruit and vegetables. Seventy participants took part in the second experiment, in which we replicated the same protocol, but using a pear odorant as the cue. The results showed that participants in the pear-scent condition were significantly more likely than those in the control condition to choose desserts with fruits, but not starters or main courses with vegetables. These results indicate that the non-conscious perception of a fruity odour may activate a 'fruit and vegetables' concept, but also a concept of the context of consumption. Moreover, they support the idea of priming effects 'specific to a food cue'.
\end{abstract}

Keywords: Priming; Food choice; Odour; Olfactory food cue; Implicit concept activation. 


\section{Introduction}

In cognitive psychology, it is now well-established that the perception of a stimulus, whether consciously/attentively processed or not, can implicitly activate high-level concepts that may influence behaviour, and not only trigger direct effects (like flight or avoidance, if the stimulus corresponds to an alarm signal for example). These implicit concept activations can be explored with a paradigm called priming (Schacter, 1992). In the first phase, participants are exposed incidentally to a stimulus called prime, which can belong to any sensory modality (visual, auditory, olfactory Etc.). Exposure to the stimulus is then inconspicuous and 'forced'. During this exposure, mental representations related to the prime are activated (Schneider, \& Shiffrin, 1977; Shiffrin, \& Schneider, 1977). In the test phase, the non-conscious effects of this activation are evaluated using indirect tests. A priming effect results in an increase or a decrease in accuracy or performance during an indirect test, even though the participant has no conscious motivation to do so. Priming has been used in several fields of investigation, and is notably well described in the visual and semantic domains (Aarts, \& Dijksterhuis, 2003; Aarts, Gollwitzer, \& Hassin, 2004; Bargh, Chen, \& Burrows, 1996; Bargh, Gollwitzer, LeeChai, Barndollar, \& Trotschel, 2001; Chartrand, \& Bargh, 1996; Custers, \& Aarts, 2005, 2007; Kawakami, Dovidio, \& Dijksterhuis, 2003; Macrae, \& Johnston, 1998). Three generalisations can be made about these studies. Firstly, priming effects occur if mental representations related to the prime and links between these representations pre-exist for participants, and if these links are strong enough. Secondly, the stronger the links, the more apparent the effects of priming should be. Thirdly, if the priming effect corresponds to the production of a particular behaviour, participants must be in a context where the expression of this behaviour of interest is relevant.

To date, very few studies have used the priming paradigm to investigate the olfactory modality, but one striking example is Holland et al.'s study (Holland, Hendriks, \& Aarts, 2005). In this experiment, participants were first asked to fill in a questionnaire in a booth with or without the odorant of a citrus-scented cleaner. Then, they performed a lexical decision task, in which they had to determine as quickly and as accurately as possible, if a letter-string appearing on a computer screen corresponded to an existing word or to a 'nonword' (i.e. a letter-string with no meaning). When exposed incidentally to the citrus odorant, participants showed shorter reaction times for cleaning-related words in the lexical decision task. Then, they moved to another room and were asked to eat a crumbly biscuit. Results showed that participants removed the biscuit crumbs more often in the scent condition even 
though they had not noticed the citrus odour in the booth. These findings suggest that (1) the non-conscious perception of a citrus odour creates a semantic association; (2) this semantic association activates the behavioural concept of cleaning; and (3) the odour impacts behaviour even if people are not conscious of it. This study illustrates the existence of a link between perception and action by revealing the non-conscious influence that olfactory cues can have on thinking and doing (Dijksterhuis, \& Bargh, 2001).

In the food domain, studies using the priming paradigm have already been conducted, and have been largely devoted to the specificity of restrained eaters' responses to food cues (Anschutz, Van Strien, \& Engels, 2008; Coelho, Polivy, Herman, \& Pliner, 2009; Fedoroff, Polivy, \& Herman, 1997, 2003; Fishbach, Friedman, \& Kruglanski, 2003; Papies, \& Hamstra, 2010; Papies, Stroebe, \& Aarts, 2007, 2008, 2009; Stroebe, Mensink, Aarts, Schut, \& Kruglanski, 2008). In one of their experiments, Fishbach et al. (2003) assigned women concerned about their weight to a diet prime condition or a control condition. In the diet prime condition, participants were brought into a room containing nutrition, exercise and dietrelated magazines. In the control condition, participants were brought into another room that merely contained a variety of magazines about the economy and geography of the United States. All of the participants performed a lexical decision task, and then chose a gift, either a chocolate Twix ${ }^{\circledR}$ bar or an apple. Results showed that the diet-primed individuals had shorter reaction times for the target word 'diet', suggesting the neural activation of a 'diet' related concept. Furthermore, they chose an apple as a gift more frequently than did participants in the control condition.

Our study was designed in the same manner, but an olfactory prime was used. The aim was to highlight a link between the perception of a fruity odour and subsequent food-related behaviour, through the activation of the concept 'fruit and vegetables'. In the priming phase, participants were first asked to complete a 'lure' categorisation task in a room with or without a fruity odorant. Then, they performed two indirect tests. The first test was a lexical decision task, including non-words and different types of words, among which some were related to fruit or vegetables (target words), some were related to high-energy foods, and some were not related to food. The second test was a menu task that measured intentions of food choices between fruit and vegetables items and high-energy food items. We hypothesised that individuals exposed to a fruity odorant may show higher reaction speeds for fruit and/or vegetable-related words in the lexical decision task, and higher frequency of fruit and/or vegetables choices on the menu card compared with individuals in the control condition. We 
ran two experiments using an olfactory prime, the first with a melon odour and the second with a pear odour.

\section{Experiment 1}

For this first experiment, a melon odorant was chosen as the olfactory prime. According to Chrea et al. (Chrea, Valentin, Sulmont-Rossé, Nguyen, \& Abdi, 2005), the odour of melon was rated as being highly typical of the fruit category which means it is a good choice as a prototypic fruity odour. A preliminary experiment run with 23 participants different from those in the present experiment confirmed the result obtained by Chrea et al., namely that the odour of melon was rated as being highly typical of the fruit category: the mean rating on a 10 -cm scale was $M=8.9 ; S E=0.34$.

\subsection{Material and methods}

\subsubsection{Participants}

Fifty-eight participants were recruited and randomly assigned to either a melon-scent condition (19-43 years old; mean age $=28$ years; 10 males and 19 females) or a control condition (19-47 years old; mean age $=27$ years; 10 males and 19 females). To participate in the study, candidates needed to possess a normal sense of smell, normal vision and have normal body weight (Body Mass Index between 19 and $25 \mathrm{~kg} / \mathrm{m}^{2}$ ). Candidates with dyslexia, food allergies or on a diet were excluded, as were those who had already taken part in a memory or priming study. In order to ensure that participants were unaware of the real purpose of the experiment (i.e. studying olfactory priming), they were told that the experiment aimed to study how people categorise environmental information. They were invited for a one-hour session during lunch-time (i.e. from 12:00 till 13:00). They were asked not to wear perfume, and not to smoke during the hour preceding the session. The experimental protocol was approved by the Comité de la Protection des Personnes Est I (Research Ethics Committee) of Dijon. In accordance with the procedures of this regulatory body, the participants received written and oral information about the study before signing a consent form. In return for their participation, they received a $€ 10$ voucher.

\subsubsection{Olfactory stimulus}

The melon food aroma sold by Meilleur du Chef(C) was selected on the basis of two preliminary experiments run with participants different from those in the present experiment. In the first experiment, $24 \%$ of 22 participants identified this aroma correctly during a free 
identification task, and 100\% identified it correctly during a 4-alternative-forced-choice identification task. In the second experiment, 23 participants rated the melon aroma on a 10cm scale as highly familiar $(M=8.1 ; S E=0.52)$, and $48 \%$ declared that the aroma evoked the desire to consume fresh fruit and/or vegetables. The melon odorant was encapsulated, and was diffused with a scent diffuser (Scentys4 \#PSIA-J-000018 v.1.00, Scentys@). Two 60-s puffs were diffused in the waiting room $30 \mathrm{~min}$ before the session began. Following the procedure, the odour intensity was very low in the room so that participants would not consciously notice the odour. This was checked with seven members of the laboratory staff, who were not informed about the presence of this aroma. These people were not included in the main experiment.

\subsubsection{Procedure}

All of the participants were seated for precisely $10 \mathrm{~min}$ in a waiting room where they performed a 'lure' categorization task. This waiting room was non-odorized in the control condition and melon-odorized in the scent condition. The 'lure' task consisted in sorting vehicles (cars, bikes, trains etc.) on the basis of their similarity. An experimenter checked that the 10 min spent in the waiting room were quiet, and that the participants did not talk to each other. Then, they were taken to the test room and seated in individual booths. First of all, they completed a lexical decision task during which they had to indicate as quickly and accurately as possible whether a letter-string appearing on a computer screen was an existing word or not. Following this, they were asked to choose a starter, a main course and a dessert from a list presented as a 'restaurant menu' (menu task). Finally, participants were asked to complete two questionnaires, an 'Investigation' Questionnaire to ascertain that they had not suspected the real goal of the study, and to check that they had not noticed or identified the prime in the waiting-room; and the Three-Factor Eating Questionnaire, to determine if there were some restrained eaters among the participants (Stunkard, \& Messick, 1985).

\subsubsection{Lexical decision task}

The task included a familiarisation phase during which participants performed six trials, and an experimentation phase during which they performed 96 experimental trials in a random order. This phase was interrupted with a break every 32 trials. Each trial proceeded as follows: participants were asked to stare at a cross in the middle of the computer screen for 2 $\mathrm{s}$, then a letter-string appeared in the centre of the screen until they answered by pressing a 'yes' or 'no' key on the keyboard, and a blank screen finally appeared for a break of $1 \mathrm{~s}$ 
before the next trial. The 96 experimental trials included 48 pronounceable non-words (plour, balbu, coumete for example), and 48 words. Among these 48 real words, 24 were neutral and non-food related (e.g. French words for 'home', 'suit', 'clear'); 12 were related to high-energy foods (e.g. French words for 'cream', 'cake', 'sugar'); and 12 were related to fruit or vegetables (e.g. French words for 'salad', 'apple', 'apricot'), including the word 'melon'. The letter-strings were chosen by taking into account the number of letters (5-7), the number of syllables (as many strings with 1, 2 or 3 syllables in each category - non-words, neutral words, high-energy-food-related words and fruit and vegetable-related words), and by respecting the frequency of the occurrence of letters in the French language for non-words. Stimulus presentation, timing, and data collection were implemented on a PC equipped with a 14-inch LCD colour screen, using dedicated software developed by a UMR CSGA engineer. The participants were seated in front of the screen at a typical viewing distance of about 65 $\mathrm{cm}$.

\subsubsection{Menu task.}

For each course category of a typical French meal (starter, main course and dessert), 10 choices were proposed, 5 items corresponding to high-energy foods vs. 5 items corresponding to foods containing fruit and/or vegetables (Table 1). Participants were asked to select one item for each course category. The selection of the menu items had previously been validated by a preliminary experiment run with 14 subjects who did not participate in the present experiment. Hedonic ratings were recorded for each item using a 10-cm scale anchored with the statements "I am not going to like it at all"/"I am going to like it very much". Results showed no significant difference between the 'fruit and vegetables' items and the 'high energy' items (starter: $F_{(1,117)}=0.09 ; p=.78$; main course: $F_{(1,117)}=0.01 ; p=.92$; dessert: $\left.F_{(1,117)}=2.46 ; p=.16\right)$. It should be noted that none of the items was related to the food 'melon'. In fact, items were chosen in order to highlight an indirect link between the exposure to the melon odorant and the intentions of choice.

[Insert table 1 about here]

\subsubsection{3. 'Investigation' Questionnaire}

Participants were asked to write down in a few words what they believed to be the goal of the study they had just taken part in, if something had surprised them during the study, and if so, if they thought that it could have influenced their performance in any of the tests.

\subsubsection{Three-Factor Eating Questionnaire}


We used the French validated version of the Three-Factor Eating Questionnaire (Stunkard, \& Messick, 1985), which includes three factors: dietary restraint, (21 items), disinhibition (16 items), and hunger (14 items).

\subsubsection{Data analyses}

With regard to the lexical decision task, incorrect responses ('no' for real words, or 'yes' for non-words) were excluded from the analyses (2.2\%). Individual reaction times were transformed using a $1 / \mathrm{Y}$ transformation (reaction speed). This transformation improves the symmetry of the distributions (Ratcliff, 1993). Consequently, outliers disappeared after transformation, and variance homogeneity was obtained. This avoided data suppression used classically in lexical decision tasks to remove outliers. With regard to the menu task, the proportion of 'fruit and vegetables' choices was determined for each group and for each dish category (starter, main course and dessert).

Statistical analyses were conducted using SAS/STAT® statistical software package version 9.1 (SAS Institute Inc., Cary, USA). For the reaction speed, all of the analyses of variance (ANOVA) were performed with the general linear model procedure of SAS (PROC GLM). Post-hoc comparisons of means were computed for each significant factor by using the 'leastsquare means' statement of the general linear model procedure. All of the results reported here were significant at a level of 0.05 unless otherwise stated. Means $(M)$ are given with associated standard error $(S E)$. As far as the proportion of fruit and vegetable choices is concerned, a logit model (generalised linear model with binomial distribution and logit link) was performed with the generalised linear model procedure of SAS (PROC GENMOD).

\subsection{Results}

One participant in the melon-scent condition remembered explicitly smelling an odour in the waiting room and was excluded from all the analyses.

\subsubsection{Lexical decision task}

Individual means of reaction speeds were computed for each word category (non-words, neutral words, high-energy foods related words and fruit and vegetables related words). These means were then submitted to an ANOVA with condition (control; melon-scent), word category and the interaction between the two as fixed factors, and subject (condition) as a random factor. Results showed a significant word category effect $\left[F_{(3,165)}=89.37 ; p<.001\right]$, with participants answering more slowly for non-words than for words (Fig. 1). No significant 
condition effect was observed $\left[F_{(1,55)}=0.13 ; p=.72\right]$, nor a significant condition $*$ word category interaction $\left[F_{(3,165)}=0.65 ; p=.59\right]$, which ruled out a 'general' priming effect (i.e. higher reaction speed for all fruit and vegetable-related words).

[Insert figure 1 about here]

To further check the existence of a priming effect 'specific to a food cue', a similar analysis was conducted on the two-syllable letter-strings, to compare mean reaction speeds for the word 'melon', with the mean reaction speeds for the other fruit and vegetable-related words, the high-energy-food-related words, the neutral words and the non-words (Fig. 2). The ANOVA revealed a significant condition $*$ word category interaction $\left[F_{(4,219)}=2.45 ; p<.05\right]$. Post-hoc analyses showed that reaction speed for the word 'melon' was significantly higher in the melon-scent condition than in the control condition $(p<.01)$. Furthermore, participants in the melon-scent condition answered faster for the word 'melon' than for the other fruit and vegetable-related words $(p<.01)$. No such difference was observed in the control condition $(p$ $=.30$ ). The same analysis performed for each of the other two-syllable fruit and vegetablerelated words did not reveal any such effect for these words.

[Insert figure 2 about here]

\subsubsection{Choices on a restaurant menu card}

To compare the proportions of 'fruit and vegetables' choices vs. 'high-energy food' choices, a logit model was performed by course category, with condition (control; melon-scent) as a factor, and unilateral tests. Results showed no significant difference for the main course (deviance $=0.14 ; d f=1 ; p=.35 ;$ ) or the dessert (deviance $=0.00 ; d f=1 ; p=.47)$, but a tendency for the starter (deviance $=2.49 ; d f=1 ; p=.06$ ). In fact, participants primed with the odour of melon tended to choose starters with vegetables more often than did participants in the control condition (Fig. 3).

[Insert figure 3 about here]

\subsubsection{Three-Factor Eating Questionnaire}

In accordance with previous research, dietary restraint was treated dichotomously, with female participants classified as restrained eaters if they scored 10 or above and male participants classified as restrained eaters if they scored 7 or above (Tepper, Trail, \& Shaffer, 1996). A Chi-square analysis revealed no difference between the percentage of restrained eaters in the melon-scent condition (38\%) and the percentage of restrained eaters in the control condition $\left(21 \% ; \chi^{2}=1.83 ; p=.18\right)$. It should be noted that restrained eaters were not 
significantly more likely than unrestrained eaters to choose starters with vegetables during the menu task $(71 \%$ of the restrained eaters chose a starter with vegetables vs. $58 \%$ of the unrestrained eaters; $\chi^{2}=0.73 ; p=.39$ ).

\subsection{Discussion}

This first experiment was designed to determine whether non-conscious exposure to a melon odour might activate a 'fruit and vegetables' concept, which would then have an impact on reaction speed for fruit and vegetable-related words in a lexical decision task, and on the frequency of fruit and vegetables choices on a restaurant menu card. In fact, regarding the results of the lexical decision task, it seems that exposure to a melon odour rather activates a 'melon' concept. Participants in the melon-scent condition answered faster for the word 'melon' than did control participants, while no such effect was observed for the other fruit and vegetable-related words. However, regarding the result of the menu task, it seems that the activation of a 'melon' concept may in turn activate both the concept 'fruit and vegetables' and the concept 'starter' which corresponds to the context in which melon is mainly consumed in France (Baros, 2009). In fact, participants in the melon-scent condition tended to choose more starters with vegetables than did participants in the control condition, while no such effect was observed for desserts. In other words, it seems that a non-consciously perceived fruity odour may activate a 'fruit and vegetables' concept, but also the concept relative to the context of consumption. To further investigate this hypothesis, we conducted a second experiment in which the odour of a fruit mainly consumed for dessert (i.e. pear odour) was used as the olfactory prime.

\section{Experiment 2}

The pear odorant was chosen as it represents a fruit mainly consumed as a dessert. According to a preliminary experiment run with 23 participants different from those in the present experiment, the odour of pear was rated as being typical of the fruit category: the mean rating on a $10-\mathrm{cm}$ scale was equal to $M=7.1 ; S E=0.63$.

\subsection{Material and methods}

\subsubsection{Participants}

Seventy participants were recruited using the same criteria as in Experiment 1 and they were randomly assigned to either a pear-scent condition $(18-48$ years old; mean age $=28$ years; 17 
males and 23 females) or a control condition (18-45 years old; mean age $=29$ years; 11 males and 19 females).

\subsubsection{Olfactory stimulus}

The pear food aroma sold by Meilleur du Chef(C) was selected on the basis of the same two preliminary experiments described in Experiment 1 for the selection of the melon food aroma. According to these preliminary experiments, $24 \%$ of 22 participants identified correctly this aroma through a free identification task, and $76 \%$ identified it correctly through a 4 alternative-forced-choice identification task. Twenty-three participants rated the pear aroma on a $10-\mathrm{cm}$ scale as familiar $(M=6.4 ; S E=0.63)$, and $17 \%$ declared that this aroma evoked the desire to consume fresh fruit. The odorization procedure was the same as in Experiment 1, except that three 30 -s puffs were diffused 30 min before the session began.

\subsubsection{Procedure}

The priming procedure was identical to that in Experiment 1. During the test phase, participants completed first the lexical decision task and then the menu task. They were then asked to choose between an apple compote or a slice of brownie as a gift for their participation (choice of a snack). They finally completed the 'Investigation' Questionnaire.

The lexical decision task was the same as in Experiment 1, with 48 non-words, 24 neutral words, 12 words related to high-energy foods and 12 words related to fruit or vegetables, including the word 'pear'. Concerning the menu task, a preliminary experiment run with 20 subjects who did not participate in the present experiment enabled to select new dessert items unrelated to the fruit 'pear' (Table 2.). Hedonic ratings were recorded for each item using 10$\mathrm{cm}$ scales. No significant differences for hedonic ratings were found between the 'fruit and vegetables' items and the 'high-energy' items (starter: $F_{(1,189)}=0.05 ; p=.83$; main course: $F_{(9,189)}=1.54 ; p=.25$; dessert: $\left.F_{(1,189)}=0.49 ; p=.50\right)$. Concerning the choice of a snack, two snacks were proposed, one unrelated (slice of brownie) and one related (apple compote) to the 'fruit and vegetables' concept. Participants were asked to select one of these snacks as a gift for their participation.

[Insert table 2 about here] 


\subsubsection{Data analyses}

The analyses conducted were the same as in Experiment 1. With regard to the choice of a snack, the proportion of 'fruity' choices was determined for each group, and a similar logit model as for the menu task was used to analyse these data.

\subsection{Results}

No participant in the pear-scent condition remembered explicitly smelling an odour in the waiting room.

\subsubsection{Lexical decision task}

Mean reaction speeds for each word category (non-words, neutral words, high-energy-foodrelated words and fruit and vegetable-related words) were submitted to an ANOVA with condition (control; pear-scent), word category and the interaction between the two as fixed factors, and subject (condition) as a random factor. Results showed a significant word category effect $\left[F_{(3,203)}=130.15 ; p<.001\right]$, with participants answering more slowly for nonwords than for words. No significant condition effect was observed $\left[F_{(1,203)}=0.43 ; p=.51\right]$, nor a significant condition * word category interaction $\left[F_{(3,203)}=0.18 ; p=.91\right]$. As in Experiment 1, this result ruled out a 'general' priming effect. The similar analysis, conducted on the two-syllable letter-strings was performed to compare mean reaction speeds for the word 'pear', with the mean reaction speeds for the other fruit and vegetable-related words, the high-energy-foods-related words, the neutral words and the non-words. The ANOVA did not reveal a significant condition $*$ word category interaction $\left[F_{(4,268)}=1.39 ; p=.24\right]$. Participants in the control condition answered as fast as participants in the pear-scent condition for the word 'pear'.

\subsubsection{Choices on a restaurant menu card}

A logit model was performed by course category, with condition (control; pear-scent) as a factor, and unilateral tests. Results showed no significant difference for the starter (deviance $=$ $0.23 ; d f=1 ; p=1.26$ ) or the main course (deviance $=0.61 ; d f=1 ; p=.86$ ). But the analyses revealed that participants primed with the odour of pear chose desserts with fruits more often $($ deviance $=3.02 ; d f=1 ; p<.05)($ Figure 4$)$.

[Insert figure 4 about here] 


\subsubsection{Choice of a snack}

A logit model was performed with condition (control; pear-scent) as a factor, and unilateral tests. The analyses revealed a tendency (deviance $=2.55 ; d f=1 ; p=.06$ ). In fact, participants primed with the odour of pear tended to choose desserts with fruit more often than did participants in the control condition (Figure 4).

\section{General discussion}

The results of the second experiment did not reveal any priming effect of the odour of pear on the lexical decision task. Nevertheless, exposure to the odour of pear had a clear impact on food choices. In fact, participants in the pear-scent condition chose a dessert with fruits on a menu significantly more frequently, and they tended to choose compote as a gift more often than did participants in the control condition. In line with the results of Experiment 1, these results seem to indicate that a non-consciously perceived odour of pear may activate not only a 'fruit and vegetables' concept, but also a concept of 'dessert' which corresponds to the context in which pear is mainly consumed.

The results of these two experiments were obtained in conditions in which the odorants were diffused so that their intensity was so low that participants would not consciously perceive it. Among the 69 participants in the scent conditions, only one (in Experiment 1) remembered explicitly having smelt an odour in the waiting room and was excluded from all the statistical analyses. All of the others were neither conscious of the presence of an odorant in the waiting room, nor of the impact it could have had on their performances to the experimental tests. Moreover, it should be noted that we obtained these results while the odour exposure was not concomitant with our experimental tests. In fact, in Holland et al.'s study (2005), participants performed the lexical decision task while the citrus odorant was diffused in the test room, whereas they were no longer exposed to the citrus odour when asked to eat a biscuit. In the present study, the participants were exposed to the melon or the pear odour for $10 \mathrm{~min}$, and then performed the different tasks in a non-odorized test room. All these findings lead us to assume that the processes involved in the priming effects we observed, operate at an implicit level.

While participants primed with a melon odour showed higher reaction speeds for the word 'melon' in the lexical decision task, participants exposed to a pear odour did not answer faster than control participants for the word 'pear'. This result could be explained by the fact that in the French language, the word 'pear' is twice as frequent as the word 'melon' (New, Pallier, 
Brysbaert, \& Ferrand, 2004). In fact, it is well established that the frequency of occurrence is a strong determinant of performance in word recognition tasks such as lexical decisionmaking, with high frequency words recognised more quickly than lower frequency words (Frederiksen, \& Kroll, 1976; Monsell, 1991). Concerning the results of Experiment 2, mean reaction speeds for the words 'melon' and 'pear' were submitted to an ANOVA with condition and word as fixed factors, and subject (condition) as a random factor. The results showed a significant word effect $\left[F_{(1,66)}=4.61 ; p<.05\right]$, with all of the participants answering more slowly for the word 'melon' $(M=579.56 \mathrm{~ms} ; S E=15.51)$ than for the word 'pear' $(M=$ $556.38 \mathrm{~ms} ; S E=17.68)$. Consequently, it can be hypothesised that reaction speed for the word 'pear' could be related to a 'ceiling level', which left no room for a possible increase in reaction speed in the pear-scent condition compared with the control condition.

Regarding the results for the menu task in the two experiments, two explanations may be proposed. The first is that the non-conscious perception of a fruity odour led to the activation of a 'fruit and vegetables' concept. This is evidenced by the fact that exposure to the odour of melon, which is typical of the fruit category, tended to induce more choices of starters with vegetables. This finding does not seem so surprising because fruit and vegetables are always associated in nutritional recommendations through French public health campaigns ("Eat five fruit and vegetables per day”) (Hercberg, Chat-Yung, \& Chauliac, 2008). Furthermore, fruit and vegetables are almost always gathered in the same section in markets (fruit and vegetable section), and share many common points, from both a culinary and a botanic points of view.

The second explanation is that the priming effects observed in our experiments seem to be rather 'specific to the food cue'. In fact, exposure to the odour of melon, which is mainly consumed as a starter, tended to modify choices of starters, but not of other courses, among participants in the melon-scent condition. Similarly, exposure to the odour of pear, which is mainly consumed as a dessert, had a significant impact on the choices of desserts, among participants in the pear-scent condition. In accordance with these results, several arguments in the literature suggest that these priming effects 'specific to the food cue' may be an inherent characteristic of olfactory priming in the food domain. In Fedoroff et al. (2003), exposure to a pizza odour induced greater pizza intake than that following the exposure to a cookie odour. In Coelho et al. (2009), we could even talk about priming effects ultra specific to the food cue. In fact, an odour of chocolate-chip cookies made restrained participants eat a smaller amount of (the cued) chocolate-chip cookies than restrained participants in a control condition, but had no effect on total cookie intake (cued cookies plus oatmeal-raisin, and 
double-chocolate cookies). As mentioned in the introduction, the stronger the link between a prime and a related mental representation, the stronger the priming effects should be. In the present experiments, the melon and the pear odours were perceived as familiar and were explicitly well-recognised and identified (see Sections 2.1.2 and 3.1.2). It can therefore be expected that the link between these primes and the subsequently activated concepts were quite strong and should produce even more specific priming effects. This raises the question of what kind of effect could be observed if a not well-recognised food odour or a food odour not typical of the corresponding food category was to be used. Further studies should clarify what characteristics of a food odour may be able to activate more general concepts, and have an impact not only on one course of a menu.

\section{Conclusions}

Based on the results of these two experiments, we can conclude that non-consciously perceived odours seem to have an impact on food choices, in this study, guiding participants towards more fruit and/or vegetables (Fig. 5). The results of the lexical decision task provided evidence that the non-consciously perceived odour of melon can first activate the corresponding food concept. Concerning the food-choice tasks, the results indicated that incidental exposure to the odour of melon or pear could activate a concept of 'fruit and vegetables' together with the more specific concept of the context of consumption.

[Insert figure 5 about here]

Although it was often considered in the past that "people were aware of their attitudes, beliefs, and values that guided their behaviour, and that they would be willing to reveal them if asked appropriately"(Kihlstrom, 2004), current psychological research suggest that a significant part of human feelings, behaviour and decision-making are influenced by implicit, unconscious processes (Bargh, \& Chartrand, 1999; Bargh, \& Ferguson, 2000; Dijksterhuis, Bos, Nordgren, \& van Baaren, 2006; Dijksterhuis, Smith, van Baaren, \& Wigboldus, 2005; Greenwald, \& Banaji, 1995). As Köster pointed out in his review published in 2009 (Köster, 2009), "intuitive reasoning and the clear demonstration of the unconscious nature of most of our decision making [...] probably play a more important role in food-related behaviour than anywhere else". In line with this thought, our study provides for the first time scientific evidence that a non-consciously perceived fruity odour can indirectly influence food choices. 


\section{Acknowledgments}

The Burgundy region funded the present work. The authors thank Jacques Maratray for the development of the software used in the lexical decision task; Fabienne Bouillot, Christophe Martin (Chemosens) and Valérie Feyen for their precious logistic help for the preparation of the experiment; The society Scentys for its work on the odorant encapsulation; Nicholas Winning and Didier Carnet for providing language help. The authors have no conflict of interest to disclose.

\section{References}

Aarts, H., \& Dijksterhuis, A. (2003). The silence of the library: environment, situational norm, and social behavior. Journal of Personality and Social Psychology, 84, 18-28.

Aarts, H., Gollwitzer, P. M., \& Hassin, R. R. (2004). Goal contagion: perceiving is for pursuing. Journal of Personality and Social Psychology, 87, 23-37.

Anschutz, D. J., Van Strien, T., \& Engels, R. C. M. E. (2008). Exposure to slim images in mass media: television commercials as reminders of restriction in restrained eaters. Health Psychology, 27, 401-408.

Bargh, J. A., \& Chartrand, T. L. (1999). The unbearable automaticity of being. American Psychologist, 54, 462-479.

Bargh, J. A., Chen, M., \& Burrows, L. (1996). Automaticity of social behavior: direct effects of trait construct and stereotype activation on action. Journal of Personality and Social Psychology, 71, 230-244.

Bargh, J. A., \& Ferguson, M. J. (2000). Beyond behaviorism: on the automaticity of higher mental processes. Psychological Bulletin, 126, 925-945.

Bargh, J. A., Gollwitzer, P. M., Lee-Chai, A., Barndollar, K., \& Trotschel, R. (2001). The automated will: nonconscious activation and pursuit of behavioral goals. Journal of Personality and Social Psychology, 81, 1014-1027.

Baros, C. (2009). Melon, perception et pratiques des consommateurs, bilan 2007, évolution 1998-2007. Paris: Centre Technique Interprofessionnel des Fruits et Legumes.

Chartrand, T. L., \& Bargh, J. A. (1996). Automatic activation of impression formation and memorization goals: nonconscious goal priming reproduces effects of explicit task instructions. Journal of Personality and Social Psychology, 71, 464-478.

Chrea, C., Valentin, D., Sulmont-Rossé, C., Nguyen, D. H., \& Abdi, H. (2005). Semantic, typicality and odor representation: A cross-cultural study. Chemical Senses, 30, 37-49.

Coelho, J. S., Polivy, J., Herman, C. P., \& Pliner, P. (2009). Wake up and smell the cookies. Effects of olfactory food-cue exposure in restrained and unrestrained eaters. Appetite, 52, 517-520.

Custers, R., \& Aarts, H. (2005). Positive affect as implicit motivator: on the nonconscious operation of behavioral goals. Journal of Personality and Social Psychology, 89, 129142. 
Custers, R., \& Aarts, H. (2007). In search of the nonconscious sources of goal pursuit: accessibility and positive affective valence of the goal state. Journal of Experimental Social Psychology, 43, 312-318.

Dijksterhuis, A., \& Bargh, J. A. (2001). The perception-behavior expressway: automatic effects of social perception on social behavior. Advances in Experimental Social Psychology, 33, 1-38.

Dijksterhuis, A., Bos, M. W., Nordgren, L. F., \& van Baaren, R. B. (2006). On making the right choice: the deliberation-without-attention effect. Science, 311, 1005-1007.

Dijksterhuis, A., Smith, P. K., van Baaren, R. B., \& Wigboldus, D. H. J. (2005). The unconscious consumer: effects of environment on consumer behavior. Journal of Consumer Psychology, 15, 193-202.

Fedoroff, I. C., Polivy, J., \& Herman, C. P. (1997). The effect of pre-exposure to food cues on the eating behavior of restrained and unrestrained eaters. Appetite, 28, 33-47.

Fedoroff, I. C., Polivy, J., \& Herman, C. P. (2003). The specificity of restrained versus unrestrained eaters' responses to food cues: general desire to eat, or craving for the cued food? Appetite, 41, 7-13.

Fishbach, A., Friedman, R. S., \& Kruglanski, A. W. (2003). Leading us not unto temptation: momentary allurements elicit overriding goal activation. Journal of Personality and Social Psychology, 84, 296-309.

Frederiksen, J. R., \& Kroll, J. F. (1976). Spelling and sound - approaches to internal lexicon. Journal of Experimental Psychology-Human Perception and Performance, 2, 361379.

Greenwald, A. G., \& Banaji, M. R. (1995). Implicit social cognition: attitudes, self-esteem, and stereotypes. Psychological Review, 102, 4-27.

Hercberg, S., Chat-Yung, S., \& Chauliac, M. (2008). The French National Nutrition and Health Program: 2001-2006-2010. International Journal of Public Health, 53, 68-77.

Holland, R. W., Hendriks, M., \& Aarts, H. (2005). Smells like clean spirit. Psychological Science, 16, 689-693.

Kawakami, K., Dovidio, J. F., \& Dijksterhuis, A. (2003). Effect of social category priming on personal attitudes. Psychological Science, 14, 315-319.

Kihlstrom, J. F. (2004). Implicit methods in social psychology. In C. Sansone, C. C. Morf \& A. T. Panter, The Sage handbook of methods in social psychology (195-212). Thousand Oaks: SAGE Publications Ltd.

Köster, E. P. (2009). Diversity in the determinants of food choice: a psychological perspective. Food Quality and Preference, 20, 70-82.

Macrae, C. N., \& Johnston, L. (1998). Help, I need somebody: automatic action and inaction. Social Cognition, 16, 400-417.

Monsell, S. (1991). The nature and locus of word frequency effects in reading. In D. B. G. W. Humphreys, Basic processes in reading - visual word recognition (148-197). Hillsdale, NJ: Erlbaum.

New, B., Pallier, C., Brysbaert, M., \& Ferrand, L. (2004). Lexique 2: a new French lexical database. Behavior Research Methods Instruments \& Computers, 36, 516-524. 
Papies, E. K., \& Hamstra, P. (2010). Goal priming and eating behavior: enhancing selfregulation by environmental cues. Health Psychology, 29, 384-388.

Papies, E. K., Stroebe, W., \& Aarts, H. (2007). Pleasure in the mind: restrained eating and spontaneous hedonic thoughts about food. Journal of Experimental Social Psychology, $43,810-817$.

Papies, E. K., Stroebe, W., \& Aarts, H. (2008). The allure of forbidden food: on the role of attention in self-regulation. Journal of Experimental Social Psychology, 44, 12831292.

Papies, E. K., Stroebe, W., \& Aarts, H. (2009). Who likes it more? Restrained eaters' implicit attitudes towards food. Appetite, 53, 279-287.

Ratcliff, R. (1993). Methods for dealing with reaction-time outliers. Psychological Bulletin, $114,510-532$.

Schacter, D. L. (1992). Implicit knowledge - new perspectives on unconscious processes. Proceedings of the National Academy of Sciences of the United States of America, 89, 11113-11117.

Schneider, W., \& Shiffrin, R. M. (1977). Controlled and automatic human informationprocessing -1- detection, search, and attention. Psychological Review, 84, 1-66.

Shiffrin, R. M., \& Schneider, W. (1977). Controlled and automatic human informationprocessing -2- perceptual learning, automatic attending, and a general theory. Psychological Review, 84, 127-190.

Stroebe, W., Mensink, W., Aarts, H., Schut, H., \& Kruglanski, A. W. (2008). Why dieters fail: testing the goal conflict model of eating. Journal of Experimental Social Psychology, 44, 26-36.

Stunkard, A. J., \& Messick, S. (1985). The three-factor eating questionnaire to measure dietary restraint, disinhibition and hunger. Journal of Psychosomatic Research, 29, 7183.

Tepper, B. J., Trail, A. C., \& Shaffer, S. E. (1996). Diet and physical activity in restrained eaters. Appetite, 27, 51-64. 


\section{Table 1}

Means of ratings on declared hedonicity for each item selected for the Menu task in Experiment 1. For each course category of a typical French meal (starter, main course and dessert), 10 choices were proposed, 5 unrelated and 5 related to the 'fruit and vegetables' concept. No item contained or referred to the fruit melon.

\begin{tabular}{|c|c|c|}
\hline & & $\begin{array}{l}\text { Declared } \\
\text { hedonicity }\end{array}$ \\
\hline & Starters & \\
\hline \multirow[t]{5}{*}{ 'High-energy' } & Assiette de charcuterie (various types of pork sausage) & $M=6.52 ; S E=0.73$ \\
\hline & $\begin{array}{l}\text { Terrine de foie de volaille (mixture of fowl liver baked in a pottery dish } \\
\text { called a terrine, and always served cold) }\end{array}$ & $M=5.28 ; S E=0.89$ \\
\hline & Quiche Lorraine (pie with a filling of lard, oignons, cream and eggs) & $M=6.92 ; S E=0.51$ \\
\hline & Crêpe au fromage (large, thin, wheat-flour pancake with cheese) & $M=5.56 ; S E=0.75$ \\
\hline & Beignets de crevettes (shrimp fritters) & $M=6.03 ; S E=0.79$ \\
\hline \multirow[t]{6}{*}{$\begin{array}{l}\text { 'Fruit and } \\
\text { vegetables' }\end{array}$} & $\begin{array}{l}\text { Carpaccio de légumes du soleil (very thin slices of summer vegetables, } \\
\text { marinated) }\end{array}$ & $M=6.59 ; S E=0.64$ \\
\hline & Velouté de carottes (creamy soup of carrots) & $M=6.54 ; S E=0.63$ \\
\hline & Salade de jeunes pousses (salad of young shoots) & $M=5.33 ; S E=0.62$ \\
\hline & Gaspacho de tomates (tomato gazpacho) & $M=5.30 ; S E=0.90$ \\
\hline & Salade aux asperges vertes (salad with green asparagus) & $M=5.95 ; S E=0.75$ \\
\hline & Main courses & \\
\hline \multirow[t]{5}{*}{ 'High-energy' } & Steak frites et ses trois sauces (steak, French fries and three sauces) & $M=6.95 ; S E=0.80$ \\
\hline & $\begin{array}{l}\text { Tartiflette savoyarde cuite au four (Savoyard specialty with cheese, } \\
\text { lardons and onions) }\end{array}$ & $M=6.93 ; S E=0.91$ \\
\hline & $\begin{array}{l}\text { Lasagnes bolognaise et béchamel gratinée (lasagna Bolognese and creamy } \\
\text { white sauce made with flour, butter and milk, with a topping of grated } \\
\text { cheese) }\end{array}$ & $M=6.20 ; S E=0.70$ \\
\hline & Travers de porc caramélisés en sauce (caramelised pork ribs with sauce) & $M=6.09 ; S E=0.88$ \\
\hline & Pizza calzone au feu de bois (calzone pizza cooked over a wood fire) & $M=6.64 ; S E=0.66$ \\
\hline \multirow[t]{6}{*}{$\begin{array}{l}\text { 'Fruit and } \\
\text { vegetables' }\end{array}$} & $\begin{array}{l}\text { Rôti de veau et sa julienne de légumes (roasted veal with match stick } \\
\text { strips of vegetables) }\end{array}$ & $M=6.44 ; S E=0.64$ \\
\hline & Saumon et sa fondue de poireaux (salmon and slow-simmered leeks) & $M=7.42 ; S E=0.50$ \\
\hline & $\begin{array}{l}\text { Truite en papillote et ses légumes rouges (trout baked in greased casings } \\
\text { and red vegetables) }\end{array}$ & $M=6.54 ; S E=0.77$ \\
\hline & $\begin{array}{l}\text { Faux filet et ses tomates à la provençale (sirloin steak, cut from beside the } \\
\text { fillet, and Provencal tomato) }\end{array}$ & $M=6.21 ; S E=0.72$ \\
\hline & Dinde farcie aux petits légumes (turkey stuffed with vegetables) & $M=6.05 ; S E=0.55$ \\
\hline & Desserts & \\
\hline \multirow[t]{5}{*}{ 'High-energy' } & $\begin{array}{l}\text { Profiteroles au chocolat (little choux-pastry balls filled with vanilla ice- } \\
\text { cream and served with a chocolate sauce) }\end{array}$ & $M=7.01 ; S E=0.82$ \\
\hline & Fondant au chocolat (chocolate cake, usually liquid in the middle) & $M=8.13 ; S E=0.52$ \\
\hline & Banana split (banana split) & $M=6.33 ; S E=0.88$ \\
\hline & Dame blanche chantilly (vanilla ice-cream with chocolate sauce) & $M=7.27 ; S E=0.48$ \\
\hline & Tiramisu au spéculoos (tiramisu with gingerbread) & $M=7.69 ; S E=0.51$ \\
\hline \multirow{5}{*}{$\begin{array}{l}\text { 'Fruit and } \\
\text { vegetables' }\end{array}$} & Salade de fruits du verger (orchard fruit salad) & $M=7.24 ; S E=0.50$ \\
\hline & Soupe de fraises à la menthe (strawberry soup with mint) & $M=6.81 ; S E=0.78$ \\
\hline & $\begin{array}{l}\text { Compote d'abricot et son coulis de framboise (apricot compote with a } \\
\text { raspberry thick sauce) }\end{array}$ & $M=5.10 ; S E=0.97$ \\
\hline & Mousse aux fruits rouges (frothy dessert with berries) & $M=6.60 ; S E=0.61$ \\
\hline & Carpaccio d'ananas (very thin slices of pineapple, marinated) & $M=6.91 ; S E=0.66$ \\
\hline
\end{tabular}




\section{Table 2}

Means of ratings on declared hedonicity for items of desserts selected for the Menu task in Experiment 2. 10 choices were proposed, 5 unrelated and 5 related to the 'fruit and vegetables' concept. No item contained or referred to the fruit pear.

\begin{tabular}{|c|c|}
\hline Desserts & $\begin{array}{l}\text { Declared } \\
\text { hedonicity }\end{array}$ \\
\hline $\begin{array}{l}\text { Profiteroles au chocolat (little choux-pastry balls filled with vanilla ice-cream } \\
\text { and served with a chocolate sauce) }\end{array}$ & $M=7.01 ; S E=0.56$ \\
\hline Fondant au chocolat (chocolate cake, usually liquid in the middle) & $M=7.77 ; S E=0.45$ \\
\hline Banana split (banana split) & $M=5.51 ; S E=0.68$ \\
\hline Dame blanche chantilly (vanilla ice-cream with chocolate sauce) & $M=6.17 ; S E=0.62$ \\
\hline Tiramisu au spéculoos (tiramisu with gingerbread) & $M=6.90 ; S E=0.74$ \\
\hline Salade de fruits d'été (summer fruit salad) & $M=8.16 ; S E=0.33$ \\
\hline $\begin{array}{l}\text { Brochette de fruits frais sauce exotique (skewer of fresh fruit with an exotic fruit } \\
\text { sauce) }\end{array}$ & $M=7.62 ; S E=0.42$ \\
\hline Fromage blanc et sa compotée d'abricot (cottage cheese and apricot compote) & $M=6.23 ; S E=0.49$ \\
\hline Smoothie aux fruits (fruit smoothie) & $M=6.17 ; S E=0.61$ \\
\hline Carpaccio d'ananas (very thin slices of pineapple, marinated) & $M=7.11 ; S E=0.60$ \\
\hline
\end{tabular}




\section{Figure 1}

Fig. 1. Means of reaction speeds in the control condition (white bars) and the melon-scent condition (grey bars) for each whole word category (non-words, neutral words, high-energy food and fruit and vegetables related words); 95\% Confidence Intervals; $* * * p<.001$

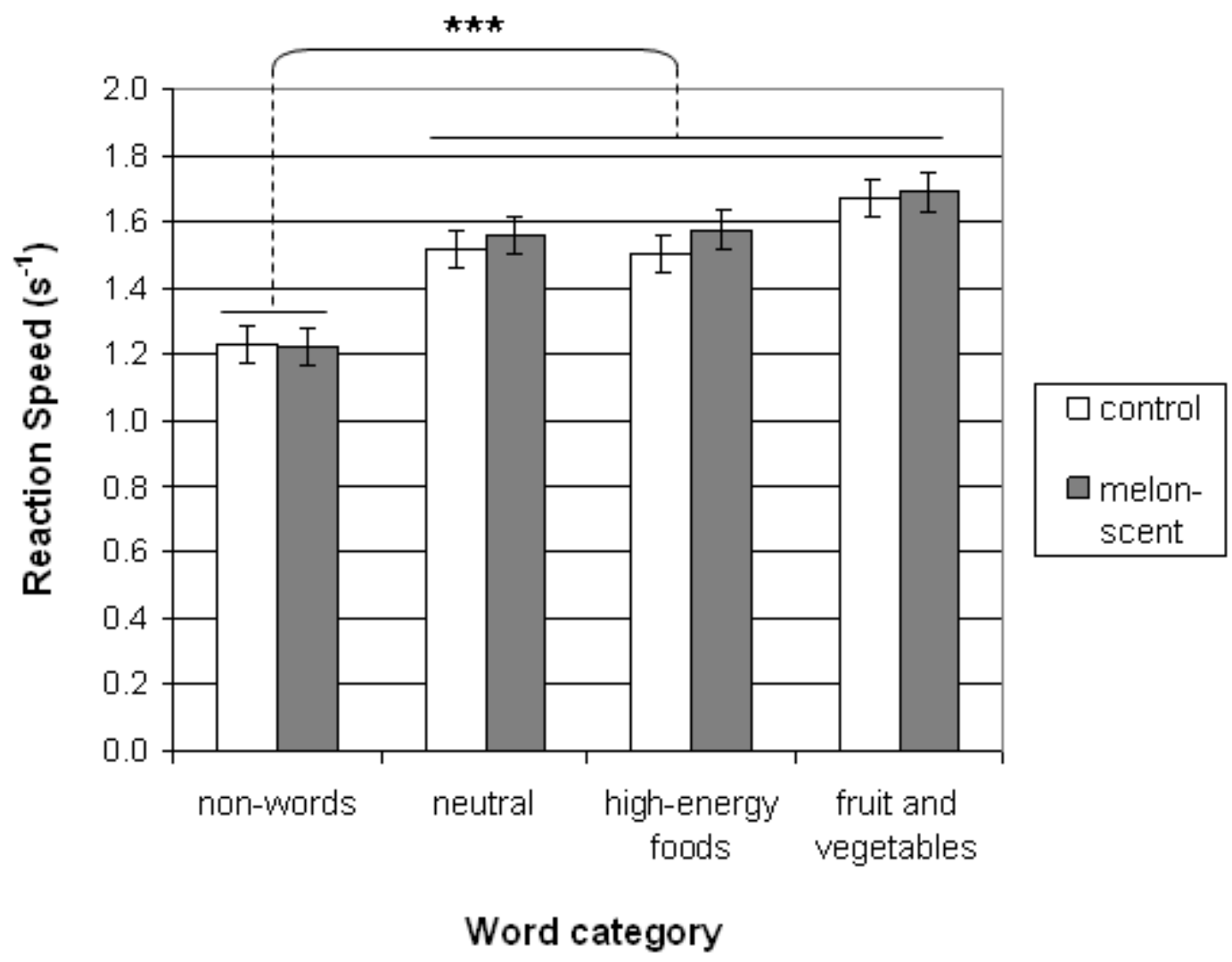




\section{Figure 2}

Fig. 2. Means of reaction speeds in the control condition (white bars) and the melon-scent condition (grey bars) for each two syllable word category (non-words, neutral words, highenergy food and fruit and vegetables related words, and the word 'melon'); 95\% Confidence Intervals; $* * p<.01$

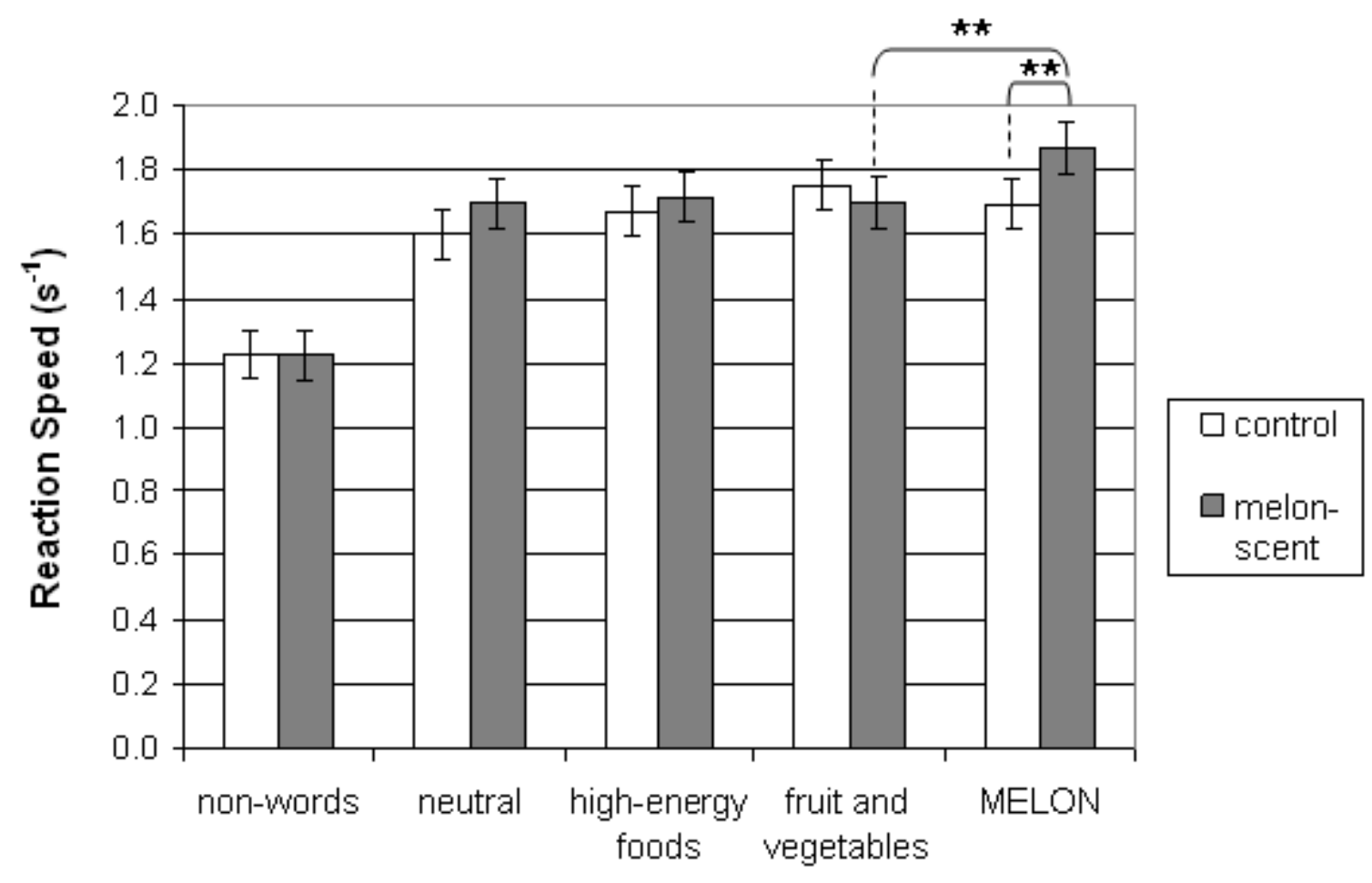

Word category 
Figure 3

Fig. 3. Proportion of choices of dishes with fruit or vegetables for each course category (starter, main course and dessert) in the control condition (white bars) and the melon-scent condition (grey bars); 90\% Confidence Intervals

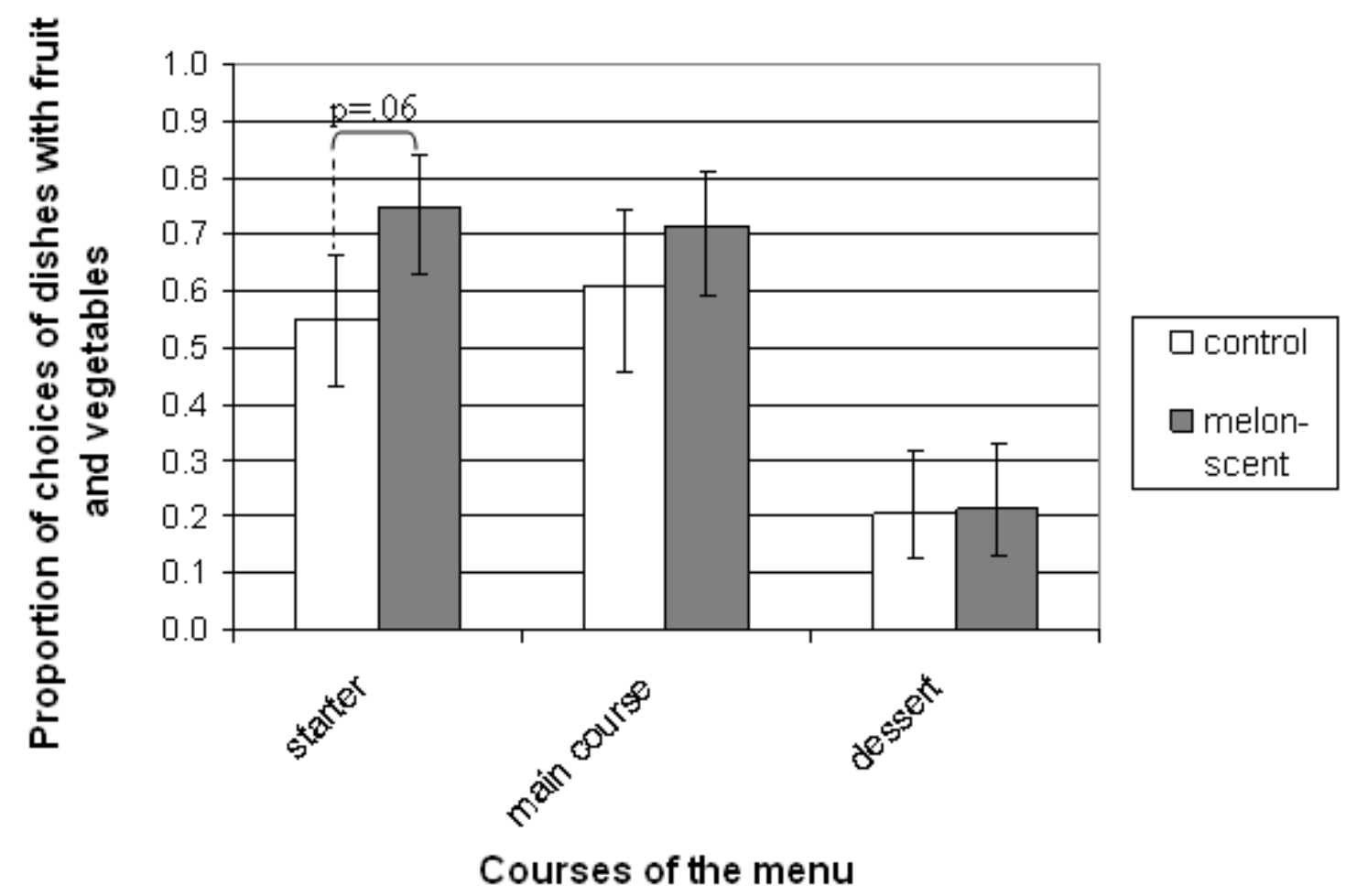




\section{Figure 4}

Fig. 4. Proportion of choices of dishes with fruit or vegetables for each course category (starter, main course and dessert) in the control condition (white bars) and the pear-scent condition (grey bars); 90\% Confidence Intervals; * $p<.05$

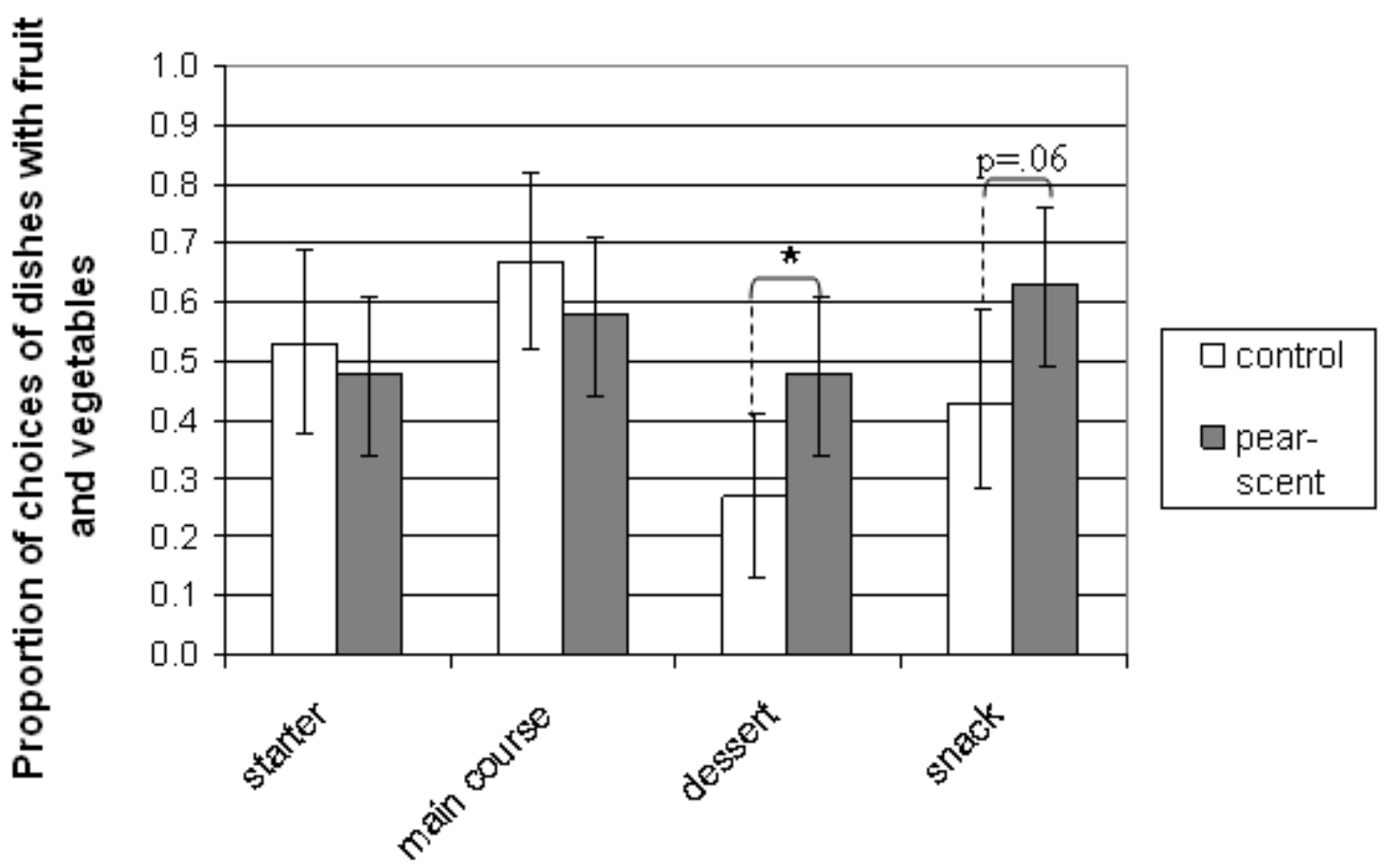

Courses of the menu 